\title{
Constitutive membrane association potentiates activation of Bruton tyrosine kinase
}

\author{
Tianjian Li ${ }^{1}$, David J Rawlings ${ }^{2}$, Hyunsun Park ${ }^{3}$, Roberta M Kato ${ }^{2}$, Owen N Witte ${ }^{1,3,4}$ and \\ Anne B Satterthwaite ${ }^{4}$
}

${ }^{1}$ Molecular Biology Institute, ${ }^{2}$ Department of Pediatrics, Division of Immunology/Rheumatology, School of Medicine, ${ }^{3}$ Howard Hughes Medical Institute, ${ }^{4}$ Department of Microbiology and Molecular Genetics, University of California, Los Angeles, California 90095, USA

\begin{abstract}
Mutations in the nonreceptor tyrosine kinase Btk result in the $B$ cell immunodeficiencies $X$-linked agammaglobulinemia (XLA) in humans and X-linked immunodeficiency (xid) in mice. Genetic and biochemical evidence implicates Btk as a key component of several B cell signaling pathways. Activation of Btk by a point mutation (E41K) within the $\mathrm{PH}$ domain (Btk*) results in fibroblast transformation and is correlated with increased membrane localization of Btk. When wild type Btk is activated by coexpression with Lyn, the tyrosine phosphorylated pool of Btk is highly enriched in the membrane fraction. To determine whether membrane association is sufficient to activate Btk, we targeted Btk to the plasma membrane using a series of fusion proteins including GagBtk, CD16Btk and CD4Btk. Constitutive membrane association greatly enhanced the ability of Btk to transform Rat2 fibroblasts in the presence of high levels of Src activity. All membrane targeted forms of Btk were highly tyrosine phosphorylated. Transformation required membrane localization, Btk kinase activity, transphosphorylation by Src family kinases, and an intact $\mathrm{SH} 2$ domain but not the $\mathrm{PH}$ or $\mathrm{SH3}$ domains. These data suggest that membrane localization is a critical early step in Btk activation.
\end{abstract}

Keywords: Btk; pleckstrin homology domain; membrane targeting; transformation

\section{Introduction}

Recruitment of cytosolic signaling molecules to the plasma membrane is a critical step in the initiation of intracellular signaling. Autophosphorylation of receptor tyrosine kinases creates docking sites to which cytoplasmic signaling proteins bind either directly (Kazlauskas et al., 1989) or via adapter molecules such as Grb2 (Downward, 1994). Signaling through receptors without intrinsic enzymatic activity relies on the activity of constitutively and/or inducibly bound kinases (Ihle et al., 1995; Chan et al., 1994; Cambier et al., 1994). Some nonreceptor tyrosine kinases (NRTKs) also communicate with the plasma membrane and elicit their function independent of cell surface receptors (Resh, 1994). Other cytosolic proteins interact with membrane associated signaling molecules such as Ras which are downstream of receptors in signal transduc-

Correspondence: ON Witte

Received 14 April 1997; revised 29 May 1997; accepted 30 May 1997 tion pathways (Vojtek et al., 1993). In many cases, cytosolic signal transducers can be artificially activated by the introduction of membrane targeting motifs such as lipid addition signals, retroviral Gag sequences, or the extracellular and transmembrane domains of cell surface proteins (Stokoe et al., 1994; Leevers et al., 1994; Aronheim et al., 1994; Quilliam et al., 1994; Klippel et al., 1996; Burgering et al., 1995; Kolanus et al., 1993; Sakai et al., 1995).

Btk is a member of the Btk/Tec family of NRTKs (Rawlings and Witte, 1995). Like Src family kinases, Btk contains Src homology (SH) SH1, SH2 and SH3 domains, but Btk exhibits several distinct structural features which distinguish these two kinase families. Btk lacks both the amino-terminal myristylation signal which targets Src to the membrane and the carboxylterminal negative regulatory tyrosine which inhibits $\mathrm{Src}$ activity. The amino-terminal region of Btk/Tec family kinases contains a pleckstrin homology $(\mathrm{PH})$ domain and a Tec homology (TH) domain (Haslam et al., 1993; Mayer et al., 1993; Vihinen et al., 1994; Rawlings et al., 1993).

Loss of Btk activity results in the immunodeficiencies X-linked agammaglobulinemia (XLA) in humans and X-linked immunodeficiency (xid) in mice (Tsukada et al., 1993; Vetrie et al., 1993; Rawlings et al., 1993; Thomas et al., 1993). These diseases are characterized by defects in B cell development and function. Genetic and biochemical analyses indicate that Btk is a component of the signal transduction pathways utilized by the B cell antigen receptor (BCR), IL-5R, IL-6R, IL-10R, CD38, and FceRI (Wicker and Scher, 1986; Hinshelwood et al., 1995; Saouf et al., 1994; Aoki et al., 1994; de Weers et al., 1994; Koike et al., 1995; Sato et al., 1994; Hitoshi et al., 1993; Matsuda et al., 1995; Santos-Argumedo et al., 1995; Go et al., 1990; Kawakami et al., 1994). Activation of Btk by either receptor crosslinking or a point mutation E41K in the $\mathrm{PH}$ domain $\left(\mathrm{Btk}^{*}\right)$ is dependent on Src family kinases (Rawlings et al., 1996; Afar et al., 1996; Park et al., 1996; Saouf et al., 1994; Mahajan et al., 1995) and is correlated with increased tyrosine phosphorylation (Rawlings et al., 1996; Li et al., 1995; Mahajan et al., 1995; Hinshelwood et al., 1995; Aoki et al., 1994; de Weers et al., 1994; Saouf et al., 1994; Sato et al., 1994; Kawakami et al., 1994; Matsuda et al., 1995) and translocation to the plasma membrane (Li et al., 1995; Kawakami et al., 1994).

Several lines of evidence suggest that PH domains play a role in signal-dependent membrane association of proteins (Hemmings 1997). The Btk PH domain has been shown to bind in vitro to $\mathrm{G} \beta \gamma$, protein kinase $\mathrm{C}$, 
phosphatidylinositol-3,4,5-triphosphate $\quad\left(\mathrm{PI}(3,4,5) \mathrm{P}_{3}\right)$ and the inositol phosphates $\mathrm{IP}_{4}, \mathrm{IP}_{5}$ and $\mathrm{IP}_{6}$ (Touhara et al., 1994; Tsukada et al., 1994; Yao et al., 1994; Salim et al., 1996; Fukuda et al., 1996). As these molecules are found at membrane proximal sites, these interactions may serve to target Btk to the membrane. Interestingly, mutations in the $\mathrm{PH}$ domain which result in XLA and xid abolish the binding of Btk to $\mathrm{PI}(3,4,5) \mathrm{P}_{3}, \quad \mathrm{IP}_{4}, \quad \mathrm{IP}_{5}$ and $\operatorname{IP}_{6}$ (Salim et al., 1996; Fukuda et al., 1996). The PH domains of other molecules have also been implicated in membrane association. Phosphatidylinositol-4,5-diphosphate $\left(\mathrm{PIP}_{2}\right)$ and many inositol phosphates bind in vitro to the $\mathrm{PH}$ domains of several proteins including $\mathrm{PLC} \delta$, dynamin, $\beta$-spectrin, pleckstrin, RasGAP and others (Harlan et al., 1994; Lemmon et al., 1995; Salim et al., 1996; Ferguson et al., 1995; Wang and Shaw, 1995; Fukuda et al., 1996). The coupling of insulin receptor substrate (IRS) to the insulin receptor is mediated by the PH domain of IRS (Yenush et al., 1996). The kinase activity of Akt is directly regulated by binding of phosphatidylinositol-3,4-bisphosphate to its $\mathrm{PH}$ domain (Franke et al., 1997). Finally, the spectrin $\mathrm{PH}$ domain has been shown to target a heterologous protein to the plasma membrane (Wang et al., 1996).

To determine whether membrane association is sufficient to activate Btk, we generated several membrane targeted forms of Btk. Constitutive membrane association greatly enhanced the activity of Btk as measured by its ability to transform fibroblasts expressing an activated Src allele. Transformation required Btk kinase activity, transphosphorylation of Btk by Src and an intact $\mathrm{SH} 2$ domain but not the $\mathrm{PH}$ or SH3 domains. These data suggest that membrane association is a critical early step in Btk activation.

\section{Results}

Tyrosine phosphorylated Btk is found predominantly in the membrane

Activation of Btk by FceRI crosslinking or the E41K mutation results in the translocation of a small fraction of Btk protein to the plasma membrane (Kawakami et al., 1994; Li et al., 1995). In addition, activation signals result in an increase in the level of phosphotyrosine on Btk (Li et al., 1995; Rawlings et al., 1996; Mahajan et al., 1995; Hinshelwood et al., 1995; Aoki et al., 1994; de Weers et al., 1994; Saouf et al., 1994; Kawakami et al., 1994; Sato et al., 1994; Matsuda et al., 1995). These observations suggest that membrane targeting and tyrosine phosphorylation are tightly integrated steps in the activation of Btk. To address this issue, we employed a vaccinia virus system in which coexpression of Btk and Lyn in NIH3T3 cells results in increased tyrosine phosphorylation of Btk and increased Btk in vitro kinase activity (Rawlings et al., 1996). The level of tyrosine phosphorylation on cytosolic and membrane associated Btk was compared (Figure 1). While Btk protein remained predominantly cytosolic when coexpressed with Lyn, the majority of tyrosine phosphorylated Btk was membrane associated (Figure 1, Lane 2). As previously described (Rawlings et al., 1996), phosphorylation of Btk required the kinase activity of both Btk (Figure 1, Lane 4) and Lyn (Figure 1, Lane
1) as well as the presence of Y551 in Btk (Figure 1, Lane 3).

\section{Alternative strategies target Btk to the plasma membrane}

These results suggest that constitutive membrane association may be sufficient to activate Btk. To address this hypothesis, a panel of fusion proteins was constructed to target Btk to the cell surface (Figure 2). Three alternative approaches were employed (see Materials and methods section for details). Each of the strategies has been previously used to direct heterologous proteins to membranes (Burgering et al., 1995; Kolanus et al., 1993; Sakai et al., 1995; Chu et al., 1994). GagBtk consisted of the first 236 amino acids of the Abelson leukemia virus Gag protein (Reddy et al., 1983) fused to the entire Btk molecule. CD16Btk encoded a transmembrane protein composed of the extracellular domain of CD16, the transmembrane domain of CD7 and the entire Btk molecule as the intracellular portion (Kolanus et al., 1993; Sakai et al., 1995). CD4Btk was constructed as an alternative transmembrane fusion protein in which the last 14 amino acids of CD4 are replaced by the full length Btk molecule (Jasin et al., 1991). All three proteins have similar in vitro kinase activity to wild type Btk and Btk* (data not shown).

To confirm that these fusion proteins were present in the membrane fraction, these proteins were expressed

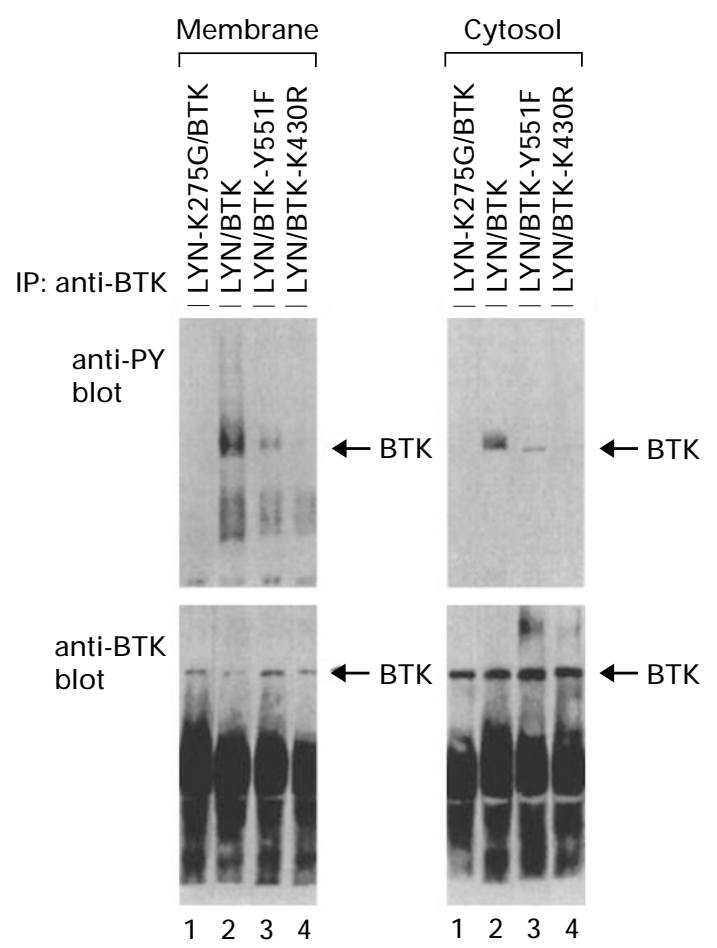

Figure 1 Tyrosine-phosphorylated Btk is membrane associated. NIH3T3 cells were coinfected with recombinant Btk and Lyn vaccinia viruses for $6 \mathrm{~h}$, and fractionated by hypotonic lysis, Dounce homogenization, and differential centrifugation. Btk was immunoprecipitated from the membrane (left) and cytosolic (right) fractions with an anti-Btk antibody and detected by immunoblotting with either an anti-phosphotyrosine antibody (4G10) or an anti-Btk antibody. Lane 1, kinase inactive Lyn(K275G) and Btk; Lane 2, Lyn and Btk; Lane 3, Lyn and Btk(Y551F); Lane 4, Lyn and kinase inactive Btk(K430R) 
in Rat2 cells expressing $\operatorname{Src}(\mathrm{E} 378 \mathrm{G})$ (see below) by retroviral infection and their subcellular localization was examined. As previously described, wild type Btk protein is cytosolic, while a small fraction of the activated allele Btk* is membrane associated (Figure 2, Li et al., 1995). All the modified allels of Btk accumulated in the membrane fraction, as predicted (Figure 2). Cytoplasmic contamination in the membrane fraction was monitored by reprobing the blot with an antibody against the cytosolic protein p120GAP (Li et al., 1995). GAP was present exclusively in the cytosolic fraction (Figure 2).

Alternative membrane localization strategies activate Btk for transformation behavior but are not sufficient to replace an activation signal from Src

Transformation of fibroblasts has been a convenient assay to identify both activating mutations in and upstream regulators of Btk (Li et al., 1995; Afar et al., 1996). Rat 2 cells provide a useful model for studying the regulation of Btk by Src family kinases. Neither the activated Src allele, Src(E378G), nor Btk* alone can transform Rat2 cells (Levy et al., 1986; Afar et al., 1996). When coexpressed, however, these two molecules send a potent transforming signal (Afar et al., 1996). Btk*, but not $\operatorname{Src}(\mathrm{E} 378 \mathrm{G})$, is highly tyrosine phosphorylated in these transformed cells, suggesting that $\operatorname{Src}(\mathrm{E} 378 \mathrm{G})$ acts upstream of and provides an activation signal for Btk (Afar et al., 1996).

When expressed in Rat 2 cells in the absence of $\operatorname{Src}(\mathrm{E} 378 \mathrm{G})$, none of the membrane localized forms of Btk produced growth in soft agar (data not shown) indicating that membrane targeting was not sufficient to replace the activation signal from Src. In order to determine whether membrane localized forms of Btk could synergize with Src, agar assays were performed with Rat2 cells coexpressing $\operatorname{Src}(\mathrm{E} 378 \mathrm{G})$ and the Btk fusion proteins. All membrane targeted alleles of Btk transformed these cells (Figure 3). GagBtk and CD16Btk gave rise to numerous large colonies (Figure 3). CD4Btk accumulated to a lower level than the other fusion proteins (Figure 4) which likely accounts for the decreased number of colonies formed

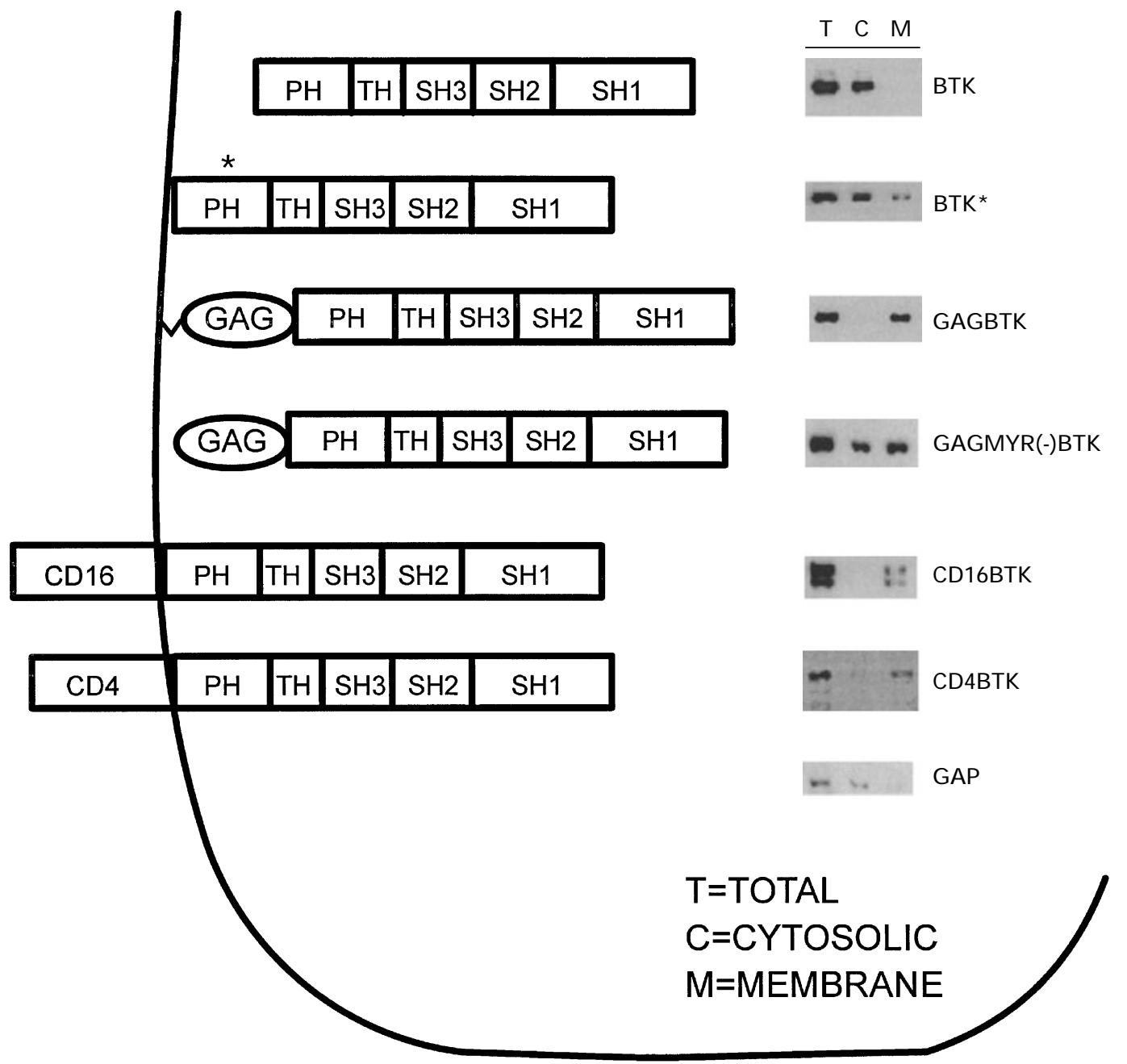

Figure 2 Different strategies to target Btk to the plasma membrane. The relative position of Btk, Btk*, GagBtk, GagMyr(-)Btk, Cd16Btk, and CD4Btk to the plasma membrane are diagrammed. Their domain structures represented as follows: SH1, the kinase domain; SH2 and SH3 the Src homology 2 and 3 domains; PH, the pleckstrin homology domain; TH, the Tec homology domain; $\mathrm{Gag}$, the first 236 amino acids of the MuLV Gag protein, CD16, the CD16 extracellular domain and CD7 transmembrane domain; CD4, the CD4 extracellular and transmembrane domains. These Btk alleles were introduced into Rat 2 cells expressing Src(E378G) by retroviral infection. Cells expressing different alleles of Btk were fractionated by hypotonic lysis, Dounce homogenization and differential centrifugation (Li et al., 1995). Fractions were subject to SDS-PAGE and immunoblotted with an anti-Btk antibody or anti-GAP antibody 


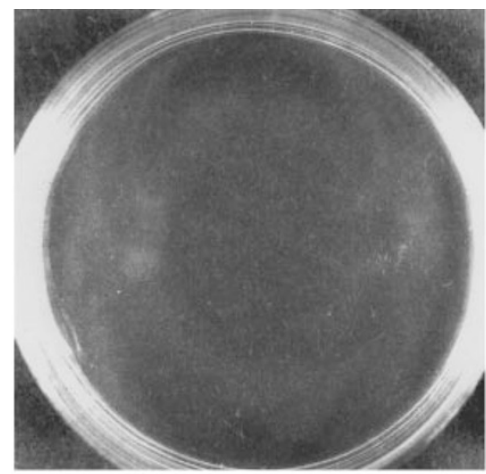

BTK 0

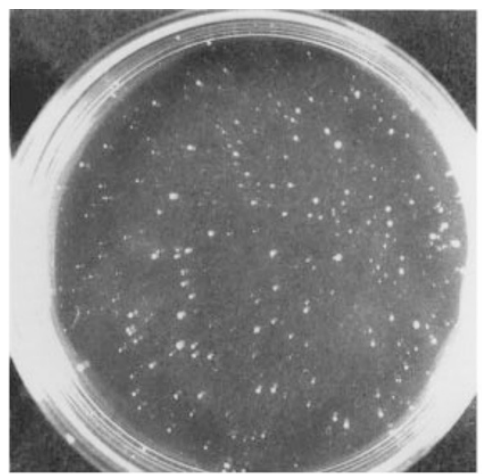

GAGBTK 300

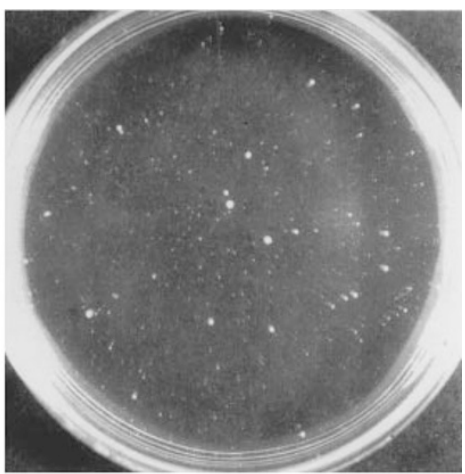

CD16BTK 240

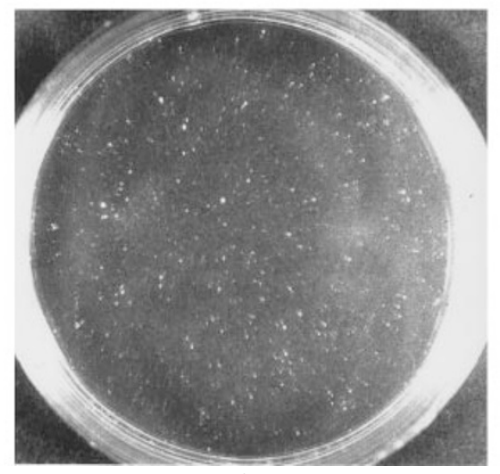

BTK* $\sim 300$

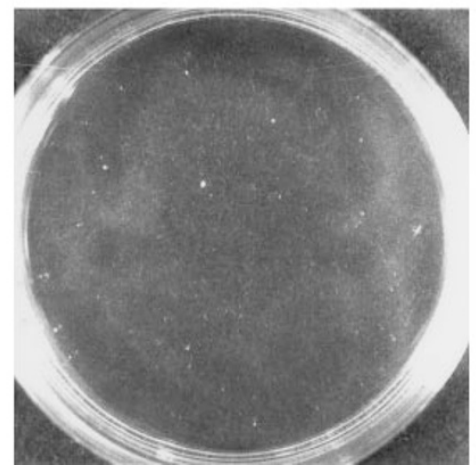

CD4BTK $\frown 50$

Figure 3 Soft agar colony formation by cells expressing Btk, Btk* and membrane targeted alleles of Btk. Rat2 cells expressing Src(E378G) were infected with the following Btk retroviruses of equivalent titer: Btk, Btk*, GagBtk, CD16Btk, CD4Btk. Three days after infection, $5 \times 10^{3}$ cells were plated into soft agar in medium containing $20 \%$ fetal calf serum in $6 \mathrm{~cm}$ plate. Colonies larger than $0.5 \mathrm{~mm}$ in diameter were counted 20 days after plating at the same time the picture was taken. The numbers presented are averages of duplicate plates from one assay and are representative of two independent experiments

by cells expressing CD4Btk relative to the other transforming alleles.

Activation of Btk by receptor crosslinking, overexpression with Src kinases, or the Btk* mutation is correlated with increased tyrosine phosphorylation of Btk (Figure 4, Li et al., 1995; Rawlings et al., 1996; Mahajan et al., 1995; Hinshelwood et al., 1995; Aoki et al., 1994; de Weers et al., 1994; Saouf et al., 1994; Kawakami et al., 1994; Sato et al., 1994; Matsuda et al., 1995). This is a result of both transphosphorylation by Src family kinases at Y551 and autophosphorylation at Y223 (Rawlings et al., 1996; Park et al., 1996). As predicted from these data, GagBtk, CD16Btk and CD4Btk (Figure 4) were all highly tyrosine phosphorylated when coexpressed in Rat2 cells with $\operatorname{Src}($ E378G). Phosphorylation is required for signaling by membrane targeted Btk, as mutations which prevent transphosphorylation by Src (Y551F) or inactive Btk kinase activity (K430R) inhibited GagBtk mediated transformation (Figure 5).

\section{Activation of GagBtk requires the myristylation signal}

It is possible that the Gag, CD16, and CD4 fusion products impart a property other than membrane association which is responsible for the activation of Btk. The Gag sequence contains a myristylation signal that is crucial for plasma membrane localization (Henderson et al., 1983). To evaluate the importance of this motif for GagBtk mediated transformation, the critical Gly residue at position two of GagBtk (Henderson et al., 1983) was mutated to Ala. The subcellular localization, transformation activity, and tyrosine phosphorylation of this myristylation defective mutant, GagMyr(-)Btk, and GagBtk were compared. GagMyr $(-) B t k$ demonstrated reduced membrane association (Figure 2) and did not transform Rat2 cells expressing $\operatorname{Src}(\mathrm{E} 378 \mathrm{G})$ (Figure 5) indicating that myristylation is required for GagBtk transformation activity. The residual membrane localization is most likely due to association with intracellular membranes, since a similar portion of this Gag protein directs $\operatorname{GagMyr}(-)$ LacZ fusion protein solely to perinuclear structures as measured by immunofluorescence (Jones et al., 1990). GagMyr(-)Btk was tyrosine phosphorylated (Figure 4), indicating that tyrosine phosphorylation of Btk is not in itself sufficient for transformation. These data also imply that targeting to the appropriate membrane is necessary for downstream signaling events.

\section{The PH domain is not required for GagBtk mediated transformation}

An intact $\mathrm{PH}$ domain is required for the function of wild type Btk in vivo (Rawlings et al., 1993; Thomas et al., 1993; Vinihen et al., 1995) and for the transforming activity of Btk* (Li et al., 1995). As previously discussed, mounting biochemical evidence 

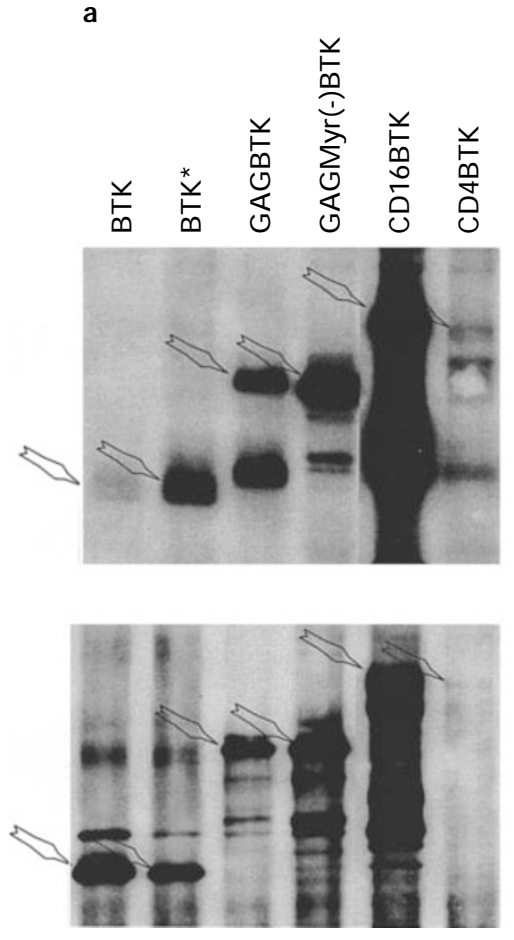

Figure 4 Increased tyrosine phosphorylation of membrane targeted alleles of Btk. Rat2 cells expressing Src(E378G) were infected with Btk retroviruses of equivalent titer expressing: (a) Btk, Btk*, GagBtk, GagMyr(-)Btk, CD16Btk, and CD4Btk or (b) Btk, GagBtk, GagBtk(R307K), GagBtk(K430R) and GagBtk(Y551), GagBtk $\Delta$ SH3, GagBtk(R28C), GagBtk $\Delta$ PH. Three days after infection, $10^{7}$ cells were lysed and Btk proteins were immunoprecipitated with anti-Btk serum. Immunoprecipitated samples were analysed by immunoblotting with anti-phosphotyrosine antibody (4G10) or affinity purified anti-Btk antibody. The positions of the Btk proteins are indicated by arrows

supports the hypothesis that $\mathrm{PH}$ domain containing proteins may be recruited to the plasma membrane via interaction with membrane proximal phospholipids or proteins (Hemmings, 1997; Harlan et al., 1994; Lemmon et al., 1995; Ferguson et al., 1995; Wang and Shaw, 1995; Salim et al., 1996; Fukuda et al., 1996; Wang et al., 1996; Touhara et al., 1994; Tsukada et al., 1994; Yao et al., 1994; Yenush et al., 1996). GagBtk proteins with $\mathrm{PH}$ domain mutations were used to determine if the Btk $\mathrm{PH}$ domain serves as essential signaling function in addition to membrane localization. Neither the mutation which results in murine xid (GagBtk(R28C)) nor complete deletion of the PH domain (GagBtk $\Delta \mathrm{PH})$ blocked GagBtk mediated transformation (Figure 5). Single mutants Btk(R28C) or Btk $\Delta \mathrm{PH}$ had no transforming activity (data not shown; Li et al., 1995). These observations indicate that constitutive membrane association alleviates the requirement for $\mathrm{PH}$ domain function in fibroblast transformation.

\section{The SH2 but not the SH3 domain is essential for} GagBtk mediated transformation

Once targeted to the membrane and activated by Src, it is likely that Btk interacts with downstream signaling molecules to elicit its function. To further clarify the domains of Btk required for these signaling events, the effect of mutations in the $\mathrm{SH} 2$ and SH3 domains of GagBtk was investigated. The mutation $\mathrm{R} 307 \mathrm{~K}$, which prevents the binding of the Btk SH2 domain to phosphorylated tyrosine residues, completely blocked the transformation activity of both Btk* and GagBtk in Rat2 cells expressing
$\operatorname{Src}(\mathrm{E} 378 \mathrm{G})$ (Figure 5, data not shown). GagBtk(R307K) retained a high level of tyrosine phosphorylation, indicating that the $\mathrm{SH} 2$ domain dependent event occurs downstream of the interaction with Src (Figure 4). Consistent with results previously described for a similar mutation in Btk*, removal of the $\mathrm{SH} 3$ domain did not impair GagBtk mediated transformation. These data indicate that the Btk SH2 but not the SH3 domain is essential for GagBtk downstream signaling and transformation of rat fibroblasts.

\section{Discussion}

\section{Membrane association is a critical step in Btk activation}

Plasma membrane association plays a critical role in the activation of many cytosolic kinases. We demonstrate here that activated Btk molecules are located predominantly in the membrane fraction. In addition, we show that constitutive membrane targeting potentiates Btk activity in a fibroblast transformation assay, the only currently available cell culture model system for Btk activation. Once targeted to the membrane, Btk requires kinase activity, transphosphorylation by Src family kinases, and an intact $\mathrm{SH} 2$ domain in order to signal. Taken together with previous data ( $\mathrm{Li}$ et al., 1995; Rawlings et al., 1996; Park et al., 1996: Mahajan et al., 1995; Saouaf et al., 1994; Kawakami et al., 1994), these results support the following working model for Btk activation. Cell surface receptor crosslinking results in both the translocation of a fraction of Btk to the 


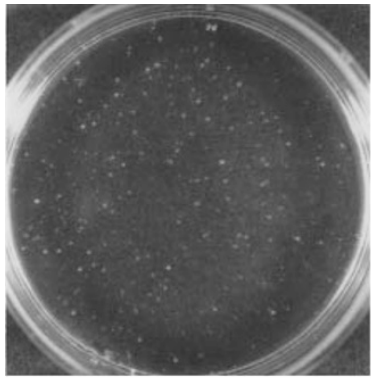

GAGBTK $\sim 300$

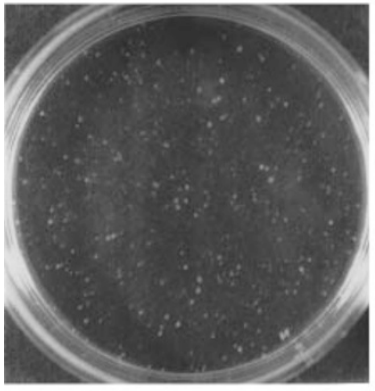

GAGBTK(R28C) 300

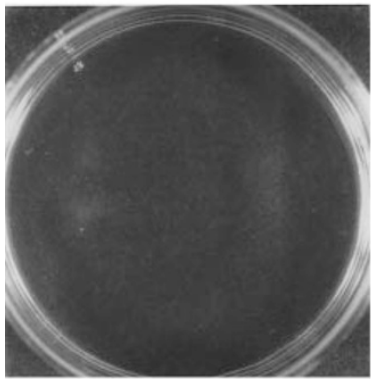

GAGBTK(R307K) 2

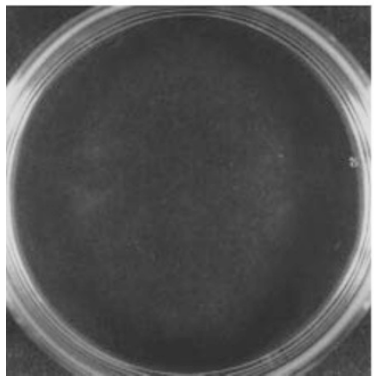

GAGBTK(Y551F) 0

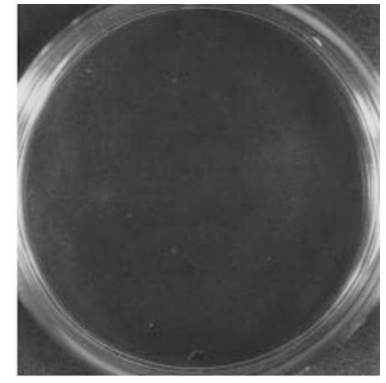

GAGMYR(-)BTK 12

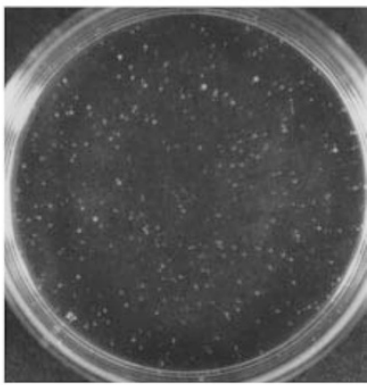

GAGBTK $\Delta \mathrm{PH} \sim 500$

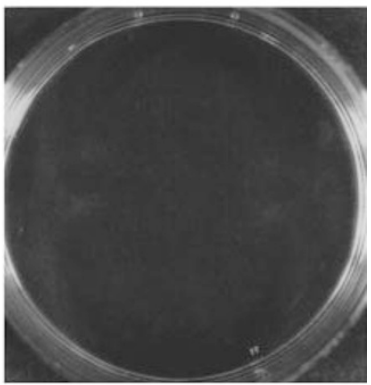

GAGBTK(K430R) 0

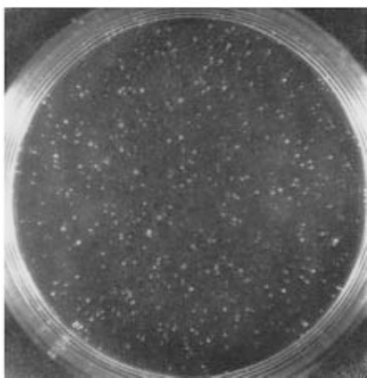

GAGBTK $\Delta$ SH3 500
Figure 5 Effect of Gag or Btk domain mutations on GagBtk transformation. Rat2 cells expressing $\operatorname{Src}(\mathrm{E} 378 \mathrm{G})$ were infected with Btk retroviruses of equivalent titer expressing: GagBtk, GagMyr(-)Btk, GagBtk(R28C), GagBtk $\Delta \mathrm{PH}$, GagBtk $\Delta \mathrm{SH} 3$, GagBtk(R307K), GagBtk(K430R), and GagBtk(Y551). Three days after infection, $5 \times 10^{3}$ cells were plated into soft agar in medium containing $20 \%$ fetal calf serum in $6 \mathrm{~cm}$ plate. Colonies larger than $0.5 \mathrm{~mm}$ diameter were counted 20 days after plating at the same time the picture was taken. The numbers presented are averages of duplicate plates from one assay and are representative of two independent experiments

plasma membrane and the phosphorylation of Btk by a two step mechanism. Transphosphorylation by Src family kinases is followed by Btk autophosphorylation. The temporal order of tyrosine phosphorylation and membrane association in a physiological setting remains to be determined.

\section{The PH domain as a membrane targeting motif}

Several lines of evidence indicate that membrane association of Btk is $\mathrm{PH}$ domain mediated. PH domain mutations result in both xid in mice and XLA in humans (Vihinen et al., 1995; Rawlings et al., 1993; Thomas et al., 1993), demonstrating the importance of this motif for Btk function. The observation that the myristylated Gag sequences alleviate the requirement for the $\mathrm{PH}$ domain suggests that the $\mathrm{PH}$ domain serves to facilitate membrane association of Btk. This is supported by the finding that the spectrin $\mathrm{PH}$ domain is sufficient to target a reporter gene to the plasma membrane (Wang et al., 1996).

Several potential $\mathrm{PH}$ domain ligands are located at membrane proximal sites and may serve as docking sites for Btk. The phospholipids and inositol phosphates $\mathrm{PI}(3,4,5) \mathrm{P}_{3}, \mathrm{IP}_{4}, \mathrm{IP}_{5}$ and $\mathrm{IP}_{6}$ bind to the Btk $\mathrm{PH}$ domain (Salim et al., 1996; Fukuda et al., 1996). These interactions are disrupted by $\mathrm{PH}$ domain point mutations found in XLA and xid (Salim et al., 1996; Fukuda et al., 1996). Recent findings from our laboratory demonstrating that PI3 kinase and Btk interact both genetically and biochemically (Zuomei Li et al., manuscript in preparation) indicate that the PI3 kinase product $\mathrm{PI}(3,4,5) \mathrm{P}_{3}$ is likely to be an important physiological ligand for the Btk $\mathrm{PH}$ domain.

Protein/protein interactions between the Btk $\mathrm{PH}$ domain and membrane associated signaling molecules may also be important for Btk membrane targeting and activation. The $\beta \gamma$ subunits of heterotrimeric $\mathrm{G}$ proteins can interact with the $\mathrm{PH}$ domain of Btk (Tsukada et al., 1994; Touhara et al., 1994), and their overexpression has been shown to increase Btk kinase activity (Langhans-Rajasekaran et al., 1995). The Btk $\mathrm{PH}$ domain can also bind to PKC isoforms (Yao et al., 1994). PKC $\beta$ knockout mice have a strikingly similar phenotype to Btk deficient mice, indicating that these two molecules may be components of the same signaling pathway (Leitges et al., 1996).

The Btk PH domain may have functions other than membrane targeting. The $\mathrm{E} 41 \mathrm{~K}$ mutation results in a small increase in the transforming activity and tyrosine phosphorylation of GagBtk (data not shown). In addition, while only a small fraction of $\mathrm{Btk}^{*}$ is membrane associated, it transforms almost as well as GagBtk and CD16Btk which are present exclusively in the membrane fraction. The E41K mutation may induce conformational changes which make Btk more accessible to Src family kinases or less accessible to downregulatory phosphatases. Alternatively, it might affect binding of the PH domain to a ligand capable of regulating Btk activity or its downstream signaling functions. While these $\mathrm{PH}$ domain functions can enhance Btk activity they are clearly not required for signaling by membrane associated forms of Btk, as a complete deletion of the PH domain from GagBtk does not block transformation.

\section{The SH2 domain plays a critical role in Btk signaling}

The SH2 domain mutation R307K impairs the ability of both GagBtk and Btk* to transform Rat2 cells expressing Src(E378G), indicating that the SH2 domain is required for Btk signaling in fibroblasts. A crucial role for the $\mathrm{SH} 2$ domain is further supported by 
several observations in other cell systems. An $\mathrm{SH} 2$ mutant of Btk cannot rescue signaling defects in a Btk deficient chicken B cell line (Takata et al., 1996), and the capacity of Btk to maintain a sustained increase in intracellular calcium is $\mathrm{SH} 2$ dependent (Zuomei Li et al., manuscript in preparation). In addition, mutations in the SH2 domain have been identified in XLA patients (Saffran et al., 1994; Ochs HD and Smith CI, 1996). The R307K mutation does not prevent Btk* transformation of NIH3T3 cells, however ( $\mathrm{Li}$ et al., 1995). This discrepancy may result from cellular changes in NIH3T3 cells which compensate for the lack of Btk SH2 domain function.

Because GagBtk(K307R) remains highly tyrosinephosphorylated, yet lacks transformation activity, the Btk SH2 domain is most likely required for signaling events downstream of activation by Src. Three proteins whose tyrosine phosphorylation depends on the $\mathrm{SH} 2$ domain of Btk have recently been identified: pp70 (Afar et al., 1996), BAP-135 (Yang and Desiderrio, 1997) and PLC $\gamma 2$ (Takada, 1996; Zuomei Li et al., manuscript in preparation). The clarification of the role of these and other molecules which interact with the Btk $\mathrm{SH} 2$ domain or require the $\mathrm{SH} 2$ domain for activation will be an important step in the understanding of Btk signaling pathways.

\section{Materials and methods}

Cell culture gene transfer and soft agar assay

NIH3T3 cells, Rat2 cells and Rat2 cell expressing Src(E378G) were grown in DMEM media supplemented with 5\% fetal calf serum (FCS). Recombinant Btk retroviral cDNAs were constructed by inserting the wild type and mutant Btk cDNAs into the pSR $\alpha$ MSVTKneo vector (Muller et al., 1991). Helper-free retroviral stocks were prepared by transient hyperexpression (Muller et al., 1991) using 293T cells to increase the viral titer (Pear et al., 1993) The titer of the viruses were measured by their ability to confer neomycin resistance to NIH3T3 cells $\left(\sim 10^{6}\right.$ colony forming unit $\left./ \mathrm{ml}\right)$. These titered retroviruses were used to infect Rat2 or Rat2 cells with $\operatorname{Src}(E 378 G)$. Recombinant Btk and Lyn vaccinia viruses were generated as described (Rawlings et al., 1996). NIH3T3 cells were infected with vaccinia viruses for $6 \mathrm{~h}$ before they were harvested for analysis.

Colony forming ability was measured by an agar assay as described (Lugo et al., 1989) usuing Rat 2 cells. Briefly, $5 \times 10^{3}$ cells infected with different Btk viruses were plated in Iscoves media containing $20 \% \mathrm{FCS}$ and $0.3 \%$ noble agar on an agar bed with $0.6 \%$ noble agar and media in each $6 \mathrm{~cm}$ plate. Colonies were counted (more than $0.5 \mathrm{~mm}$ in diameter) 2 weeks after plating.

\section{Constructs}

The Gag sequence was generated by polymerase chain reactin (PCR) using the following primer pairs: 5'-ATT GCG GCC GCACCATGGGCCAGACTGTTACC$3^{\prime}$ and 5'-AATCCATGGGTAAAGGTCAGAAGAGGA-3' and Gag-Abl (MuLV) as the template. The PCR product was subcloned into the TA cloning vector (Invitrogen). GagBtk and GagBtk(R28C) were created by insertion of Gag in front of the Btk coding sequence (wildtype or the R28C mutant respectively) at the NcoI site in the pBluescriptSK $(-)$ vector (Stratagene). The myristylation mutant, $\operatorname{Gag} \operatorname{Myr}(-) B t k$, was created similarly using a different 5' primer: 5'-ATTGCGGCCGCACCATGGCCCAGACTGTTACC-3', that changes codon 2 from Gly to Ala. GagBtk and GagBtk(R28C) were then subcloned in to the pSR $\alpha$ MSVTKneo vector (Muller et al., 1991). GagBtk(R307K), GagBtk(K430R), GagBtk(Y551F), and GagBtk $(\Delta 204-263)$ were created by replacing a HindIII fragment of GagBtk with equivalent fragments containing the indicated Btk mutations ( $\mathrm{Li}$ et al., 1995) in pSR $\alpha$ MSVTKneo. Btk $(\Delta \mathrm{PH})$ was created in two steps. First, the $5^{\prime}$ portion was amplified by PCR using primers 5'-GGACCATGGACCTGGTACAGAAA-3' and 5'-GCT GAAAAAGGTCGTGGC- $3^{\prime}$ and Btk as the template. Then a HindIII fragment of this PCR product was ligated to Btk at the HindIII site within Btk. Gag $(\Delta \mathrm{PH})$ was created by inserting the Gag sequence in front of $\mathrm{Btk}(\Delta \mathrm{PH})$, similar to GagBtk.

A PCR generated (with primers 5'-ACCATGGACTCCAGGATCCAG-3' and 5'-CGCCATGGTCTTCTTCTCAC TGAGG-3') murine CD4 fragment corresponding to the carboxyl terminal of CD4 was ligated back to CD4 to generate pSR $\alpha$ MSVCD4TKneo with an introduction of a NotI restriction site at the $3^{\prime}$ end. This CD4 construct lacks 14 amino acids at its carboxyl terminus. Btk was subcloned in frame with CD4 into $\mathrm{pSR} \alpha \mathrm{MSVCD} 4 \mathrm{TK}$ neo sequentially as a NotI-HindIII fragment and then a HindIII fragment to produce the final psR $\alpha$ MSVCD4BtkTKneo construct.

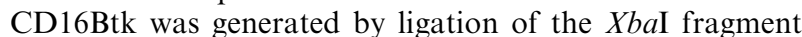
from CD16: 7 : Syk (Kolanus et al., 1993; Sakai et al., 1995) into pBluscript, followed by in flame replacement of Syk with the $N c o I / S p e I$ fragment of Btk. The resulting fragment encoding the CD16 extracellular domain, the CD7 transmembrane domain and the full length Btk protein was subcloned into the pSR $\alpha$ MSVTKneo vector by ligation into the NotI site.

\section{Protein analysis}

Total cell lysates were prepared by lysing $10^{6}$ cells in $200 \mu \mathrm{l}$ boiling $2 \times$ sample buffer $(2 \%$ SDS, $0.1 \mathrm{M}$ Tris $\mathrm{pH} 6.8,20 \%$ glycerol, $5 \% \quad \beta$-mercaptoethanol, $0.1 \%$ bromophenol blue). Immunoprecipitation and immunoblotting were done as described (Konopka and Witte, 1985). Briefly, $10^{7}$ cells were lysed on the plate with boiling cell lysis buffer $(1 \%$ Triton X$100,10 \mathrm{~mm}$ phosphate buffer $\mathrm{pH} 7.0,150 \mathrm{~mm} \mathrm{NaCl}, 500 \mu \mathrm{M}$ sodium vanadate) plus $1 \%$ SDS. The cell lysates were diluted tenfold with cell lysis buffer and clarified by ultracentrifugation at $100000 \mathrm{~g}$ for $30 \mathrm{~min}$ at $4{ }^{\circ} \mathrm{C}$. The supernatants were incubated with $10 \mu \mathrm{l}$ anti-Btk antibody at $4{ }^{\circ} \mathrm{C}$ for $2 \mathrm{~h}$. The samples were mixed with $100 \mu$ protein A Sepharose beads (suspended in five beads volume of cell lysis buffer) in the cold room for $1 \mathrm{~h}$ on a nutator and were washed three times with cell lysis buffer. For immunoblotting, immunoprecipitates or cell lysates were subjected to $10 \%$ SDS-PAGE and transferred to nitrocellulose filter. The filter was blotted with $5 \%$ skim milk in $150 \mathrm{~mm} \mathrm{NaCl}, 10 \mathrm{~mm}$ Tris $\mathrm{pH} 7.5$ and $500 \mu \mathrm{M}$ sodium vanadate for $1 \mathrm{~h}$, except for anti-phosphotyrosine blotting, which was blocked with $6 \%$ BSA in $150 \mathrm{~mm} \mathrm{NaCl}, 10 \mathrm{mM}$ Tris $\mathrm{pH} \mathrm{7.5}$, and $500 \mu \mathrm{M}$ sodium vanadate at $37^{\circ} \mathrm{C}$ for $1 \mathrm{~h}$. The filter was then sequentially blotted with primary antibodies (anti-Btk amino-terminal (Tsukada et al., 1993), $1: 500$ dilution; anti-GAP (Transduction Laboratories), 1:250 dilution, anti-phosphotyrosine (4G10), 1:1000 dilution) and secondary antibodies (horseradish peroxidase (HRP) conjugated goat-anti-rabbit or goat-anti-mouse (BioRad), $1: 5000$ dilution). Proteins were visualized by the ECL technique (Amersham).

\section{Subcellular fractionation}

Subcellular fractionation was performed as described $(\mathrm{Li}$ et al., 1995). Briefly, $10^{7}$ cells expressing Btk alleles were scraped into $1 \mathrm{ml}$ hypotonic lysis buffer (1 mM EDTA, 
$1 \mathrm{~mm}$ EGTA, $10 \mathrm{~mm} \beta$-glycerophosphate, $1 \mathrm{~mm}$ sodium vanadate, $2 \mathrm{mM} \mathrm{MgCl}_{2}, 10 \mathrm{mM} \mathrm{KCl}, 1 \mathrm{mM}$ DTT, $10 \mu \mathrm{g} / \mathrm{ml}$ leupeptin, $10 \mu \mathrm{g} / \mathrm{ml}$ aprotinin, $40 \mathrm{ng} / \mathrm{ml} \mathrm{PMSF}$ ) and were incubated on ice for $30 \mathrm{~min}$. Cells were then Dounce homogenized (30 strokes). Cell lysates were loaded onto a $1 \mathrm{M}$ sucrose cushion and spun at $1600 \mathrm{~g}$ for $10 \mathrm{~min}$. Post nuclei supernatant were spun at $100000 \mathrm{~g}$ for $30 \mathrm{~min}$. The supernatant contained the cytosolic fraction. The precipitate containing the membrane fraction was washed with the hypotonic lysis buffer twice and resuspended in hypotonic lysis buffer containing 1\% SDS in the same volume as the cytosolic fraction. It was designated the membrane fraction.

\section{References}

Afar DE, Park H, Howell BW, Rawlings DJ, Cooper J and Witte ON. (1996). Mol. Cell. Biol., 16, 3465-3471.

Aoki Y, Isselbacher KS and Pillai S. (1994). Proc. Natl. Acad. Sci. USA, 91, $10606-10691$.

Aronheim A, Engelberg D, Li N, al-Alawi N, Schlessinger J and Karin M. (1994). Cell, 78, 949-961.

Burgering BM and Coffer PJ. (1995). Nature, 376, 599-602.

Cambier JC, Pleiman CM and Clark MR. (1994). Ann. Rev. Immunol., 12, $475-486$.

Chan AC, Desai DM and Weiss A. (1994). Ann. Rev. Immunol., 12, 555-592.

Chu K and Littman DR. (1994). J. Biol. Chem., 269, 2409524101

de Weers M, Brouns GS, Hinshelwood S, Kinnon C, Schuerman RK, Hendriks RW and Borst J. (1994). J Biol. Chem., 269, 23857-23860.

Downward J. (1994). FEBS Letters, 338, 113-117.

Franke TF, Kaplan DR, Cantley LC and Toker A. (1997). Science, 275, $665-668$.

Ferguson KM, Lemmon MA, Schlessinger $\mathbf{J}$ and Sigler PB. (1995). Cell, 83, 1037-1046.

Fukuda M, Kojima T, Kabayama $\mathrm{H}$ and Mikoshiba K. (1996). J. Biol. Chem., 271, 30303-30306.

Go NF, Castle BE, Barret R, Kastelein R, Dang W, Mosmann TR, Moore KW and Howard M. (1990). J. Exp. Med., 172, $1625-1631$.

Harlan JE, Hajduk PJ, Yoon HS and Fesik SW. (1994). Nature, 371, $168-170$.

Haslam RJ, Koide HB and Hemmings BA. (1993). Nature, 363, 309-310.

Hemmings BA. (1997). Science, 275, 1899.

Henderson LE, Krutzsch HC and Oroszlan S. (1983). Proc. Natl. Acad. Sci. USA, 80, $339-343$.

Hitoshi Y, Sonoda E, Kikuchi Y, Yonehara S, Nakauchi H and Takatsu K. (1993). Intl. Immunol., 5, 1183-1190.

Hinshelwood S, Lovering RC, Benevier HC, Levinsky RJ and Kinnon C. (1995). Eur. J. Immunol., 25, 1113-1116.

Ihle JN, Witthuhn BA, Quelle FW, Yamamoto K and Silvennoinen O. (1995). Ann. Rev. Immunol., 13, 369- 398.

Jasin M, Page KA and Littman DR. (1991). J. Virol., 65, $440-444$

Jones TA, Blaug G, Hansen M and Barklis E. (1990). $J$. Virol, 64, 2265-2279.

Kaslauskas A and Cooper J. (1989). Cell, 58, $1121-1133$.

Kavanaugh WM and Williams LT. (1994). Science, 266 , $1862-1865$.

Kawakami Y, Yao L, Miura T, Tsukada S, Witte ON and Kawakami T. (1994). Mol. Cell. Biol., 14, 5108-5113.

Klippel A, Reinhard C, Kavanaugh WM, Apell G, Escobedo MA and Williams LT. (1996). Mol. Cell. Biol., 16, $4117-$ 4127.

Koike M, Kikuchi Y, Tominaga A, Takaki S, Akagi K, Miyazaki J, Yamamura K and Takatsu K. (1995). Intl. Immunol., 7, $21-30$.

\section{Acknowledgements}

We thank Dr Carrie Miceli for kindly providing us with the murine CD4 cDNA, Drs Douglas Black and Fuyuhiko Tamanoi for critical reading of the manuscript and Julia Shimaoka and Jamie White for assistance in preparation of the manuscript and figures. This work was partially supported by USPHS National Institutional Research Service Award CA-09056 (TL), a postdoctoral fellowship from Irvington Institute for Immunological Research (AS), a fellowship from Cancer Research Institute (HP), USPHS CA-12800 (PI Randolph Wall) and AR01912 and HL-9410-B (DJR) DJR is a recipient of a NIH Physician Scientist Award. ONW is an Investigator of the Howard Hughes Medical Institute.

Kolanus W, Romeo C and Seed B. (1993). Cell, 74, 171-183. Konopka JB and Witte ON. (1985). Mol. Cell. Biol., 5, $3116-3123$.

Langhans-Rajasekaran SA, Wan Y and Huang X-Y. (1995). Proc. Natl. Acad. Sci. USA, 92, 8601-8605.

Leevers SJ, Paterson HF and Marshall CJ. (1994). Nature, 369, $411-414$

Leitges M, Schmedt C, Guinamard R, Davoust J, Schaal S, Stabel S and Tarakhovsky A. (1996). Science, 273, $788-$ 791.

Lemmon MA, Ferguson KM, O'Brien R, Sigler PB and Schlessinger J. (1995). Proc. Natl. Acad. Sci. USA, 92, $10472-10476$

Levy JB, Iba H and Hanafusa H. (1986). Proc. Natl. Acad. Sci. USA, 83, $4228-4232$

Li T, Tsukada S, Satterthwaite A, Havlik MH, Park H, Takatsu K and Witte ON. (1995). Immunity, 2, 451-460.

Lugo T and Witte ON. (1989). Mol. Cell. Biol., 9, $1263-$ 1270.

Mahajan S, Fargnoli J, Burkhardt AL, Kut SA, Saouaf SJ and Bolen JB. (1995). Mol. Cell. Biol., 15, 5304-5311.

Matsuda T, Takahashi-Tezuka M, Fukada T, Okuyama Y, Fujitani Y, Tsukada S, Mano H, Hirai H, Witte ON and Hirano T. (1995). Blood, 85, 627-633.

Mayer BJ, Ren R, Clark KL and Baltimore D. (1993). Cell, 73, 629-630.

Muller AJ, Young JC, Pendergast AM, Pondel M, Landau NR, Littman DR and Witte ON. (1991). Mol. Cell. Biol., 11, $1785-1792$.

Ochs HD and Smith CI. (1996). Medicine, 75, 287-299.

Park H, Wahl MI, Afar DE, Turck CW, Rawlings DJ, Tam C, Scharenberg AM, Kinet JP and Witte ON. (1996). Immunity, 4, 515-525.

Pear WS, Nolan GP, Scott ML and Baltimore D. (1993). Proc. Natl. Acad. Sci. USA, 90, 8392-8396.

Quilliam LA, Huff SY, Rabun KM, Wei W, Park W, Broek D and Der CJ. (1994). Proc. Natl. Acad. Sci. USA, 91, $8521-8526$.

Rawlings DJ, Saffran DC, Tsukada S, Largaespada DA, Grimaldi JC, Cohen L, Mohr RN, Bazan JF, Howard M, Copeland NG, Jenkins NA and Witte ON. (1993). Science, 261, 358-361.

Rawlings DJ and Witte ON. (1995). Semin. Immunol., 7, $237-246$

Rawlings DJ, Scharenberg AM, Park H, Wahl MI, Lin S, Kato RM, Fluckiger AC, Witte ON and Kinet JP. (1996). Science, 271, 822-825.

Reddy EP, Smith MJ and Srinivasan A. (1983). Proc. Natl. Acad. Sci. USA, 80, 3623-3627.

Resh MD. (1994). Cell, 76, 411-413.

Saffran DC, Parolini O, Fitch-Hilgenberg ME, Rawlings DJ, Afar DE, Witte ON and Conley ME. (1994). N. Engl. J. Med., 330, $1488-1491$. 
Sakai I, Nabell L and Kraft AS. (1995). J. Biol. Chem., 270, $18420-18427$.

Salim K, Bottomley MJ, Querfurth E, Zvelebil MJ, Gout I, Scaife R, Margolis RL, Gigg R, Smith CI, Driscoll PC, Waterfield MD and Panayyotou G. (1996). EMBO J., 15, $6241-6250$.

Santos-Argumedo L, Lund FE, Heath AW, Solvason N, Wu WW, Grimaldi JC, Parkhouse RM and Howard M. (1995). Immunol., 85, 248-255.

Saouaf SJ, Mahajan S, Rowley RB, Kut SA, Fargnoli J, Burkhardt AL, Tsukada S, Witte ON and Bolen JB. (1994). Proc. Natl. Acad. Sci. USA, 91, 9524-9528.

Sato S, Katagiri T, Takaki S, Kikuchi Y, Hitoshi Y, Yonehara S, Tsukada S, Kitamura D, Watanabe T, Witte ON and Takatsu K. (1994). J. Exp. Med., 180, $2101-2111$.

Stokoe D, Macdonald SG, Cadwallader K, Symons M and Hancock JF. (1994). Science, 264, 1463 - 1467.

Takata M and Kurosaki T. (1996). J. Exp. Med., 184, $31-40$.

Thomas JD, Sideras Smith CIE, Vorechovsky I, Chapman V and Paul WE. (1993). Science, 261, 355-358.

Touhara K, Inglese J, Pitcher JA, Shaw G and Lefkowitz RJ. (1994). Proc. Natl. Acad. Sci. USA, 91, 11256-11260.

Tsukada S, Saffran DC, Rawlings DJ, Parolini O, Allen RC, Klisak I, Sparkes RS, Kubagawa H, Mohandas T, Quan S, Belmont JW, Cooper MD, Conley ME and Witte ON. (1993). Cell, 72, 279-290.
Tsukada S, Simon MI, Witte ON and Katz A. (1994). Proc. Natl. Acad. Sci. USA, 91, 11256-11260.

Vetrie D, Vorechovsky I, Sideras P, Holland J, Davies A, Flinter F, Hammarström L, Kinnon C, Levinsky R, Bobrow M, Smith CIE and Bentley DR. (1993). Nature, 361, 226-233.

Vihinen M, Nilsson L and Smith CI. (1994). Febs Letters, 350, 263-265.

Vihinen M, Zvelebil MJ, Zhu Q, Brooimans RA, Ochs HD, Zegers BJ, Nilsson L, Waterfield MD and Smith CI. (1995). Biochem., 34, 1475-1481.

Vojtek AB, Hollenberg SM and Cooper JA. (1993). Cell, 74 $205-214$

Wang DS and Shaw G. (1995). Bioche. Biophy. Res. Comm., 217, 608-615.

Wang DS, Miller R, Shaw R and Shaw G. (1996). Bioche. Biophy. Res. Comm., 225, 420-426.

Wicker LS and Scher I. (1986). Curr. Top. Microbiol. Immunol., 124, 87-101.

Yang WY and Desiderio S. (1997). Proc. Natl. Acad. Sci. USA, 94, 604-609.

Yao L, Kawakami Y and Kawakami T. (1994). Proc. Natl. Acad. Sci. USA, 91, 9175-9179.

Yenush L, Makati KJ, Smith-Hall J, Ishibashi O, Myers MG Jr and White MF. (1996). J. Biol. Chem., 271, 24300 24306. 